\title{
Advances in Environmental Detection and Clinical Diagnostic Tests for Legionella Species
}

\author{
Rajeshwari Vittal ${ }^{1}$ Juliet Roshini Mohan Raj ${ }^{1}$ Ballamoole Krishna Kumar ${ }^{1}$ Indrani Karunasagar ${ }^{2}$
}

\footnotetext{
${ }^{1}$ Division of Infectious Diseases, Nitte University Centre for Science Education and Research, Deralakatte, Mangaluru, Karnataka, India

2 Nitte University Centre for Science Education and Research,

Mangaluru, Karnataka, India

J Health Allied Sci ${ }^{\mathrm{NU}}$ 2022;12:168-174.
}

\begin{abstract}
Address for correspondence Juliet Roshini Mohan Raj, PhD, Division of Infectious Diseases, Nitte University Centre for Science Education and Research, Mangaluru 575 018, Karnataka, India (e-mail: julietm@nitte.edu.in; juliet.tutu@gmail.com).
\end{abstract}

\author{
Abstract \\ Keywords \\ - extrapulmonary \\ infection \\ - iron \\ - Legionella \\ - Legionella- \\ contaminated aerosol \\ - Legionnaires diseases \\ - Pontiac fever \\ - water distribution \\ system
}

Legionella is a fastidious organism that is difficult to culture in the lab but is widely distributed in environmental, domestic, and hospital settings. The clinical manifestations due to Legionella infections range from mild fever to fatal pneumonia and multiorgan pathologies. Legionella outbreaks though prevalent globally are not reported in developing countries due to difficulties in isolating this organism and the lack of simple diagnostic protocols. Here, we review the literature from across countries to present various methods used to detect Legionella from environmental and clinical samples. We compare the sensitivity and the specificity of the conventional culture-based assays with the recent methods and discuss approaches to develop better detection and diagnostic tests. With better cost-effective detection techniques and regular monitoring of the susceptible sites, which may harbor Legionella colonies, most of the Legionella infections can be prevented. As a result, considerable burden, caused by Legionella infections, on the healthcare system, in especially economically weaker countries, can be mitigated.

\section{Legionella: Discovery and General Features}

Though reported from a soldier's blood culture in the 1950s, the importance of Legionella as a human pathogen was recognized only in 1976 when an unexpected outbreak of fever with pneumonia was reported among participants of the American Legion Conference in Philadelphia, United States of America. This led to the discovery of the causative organism called Legionella and new diseases called Legionnaires disease (LD) and Pontiac fever (PF) getting added to the list of bacterial infections. ${ }^{1}$ Legionella are common in soil and aquatic systems often found associated with protists. ${ }^{2}$ The cells of Legionella are thin, pleomorphic, Gram negative, nonspore-forming bacilli with a size ranging from 2 to $20 \mu \mathrm{m}$ in length and 0.3 to $0.9 \mu \mathrm{m}$ in width. Most species are motile by means of a single polar flagellum and have pili. The members of this genera utilize amino acids rather than carbohydrates for energy and require L-cysteine and iron salts for their survival. They can withstand a wide range of temperature from 20 to $45^{\circ} \mathrm{C} .{ }^{3}$ Legionella are pervasive in all aquatic habitats and known to enter man-made water systems easily. ${ }^{2}$

Till date, about 60 species of Legionella have been documented and of these at least 24 have been found associated with human disease condition. L. pneumophila, L. longbeachae, L. anisa, L. bozemanii, and L. micdadei are commonly detected agents of Legionellosis. Other pathogens include $L$. feeleii, L. hackeliae, L. sainthelensi, L. spiritensis, L. erythra, and
DOI https://doi.org/ $10.1055 / \mathrm{s}-0041-1731863$ ISSN 2582-4287.

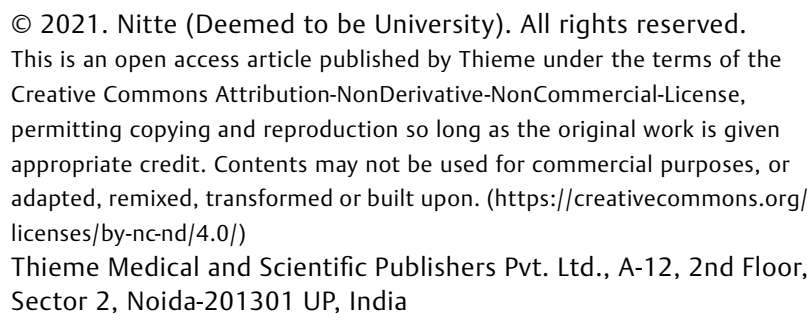


L. quinlivanii. Environmental isolates such as L. adelaidensis, L. beliardensis, L. brunensis, and L. busanensis are some of the nonpathogenic species. ${ }^{4}$

\section{Reservoirs}

Water is the primary natural reservoir, although Legionella represents a minor component accounting for less than $1 \%$ of the residential bacterial population in water. ${ }^{5}$ Legionella are found worldwide in freshwater environments such as stagnant lakes, springs, mud streams, and damp soil with relatively low concentration. However, they are rarely found in the marine ecosystem. ${ }^{6,7}$ Ocean waters receiving treated sewage contain Legionella species and their numbers do not drop even after the treatment process. ${ }^{8}$ Since Legionella are autochthonous in aquatic habitats, it is impossible to prevent their entry to public water systems. Storage tanks, decorative fountains, spa pools, ${ }^{9}$ whirlpools, air conditioning vents, cooling towers in recreational centers and water systems of homes, industries, resorts, healthcare facilities, and cruises ${ }^{10,11}$ have been identified as sources of Legionella outbreaks. The disease is mainly transmitted via air from the water source typically contracted by inhaling contaminated aerosols from anthropogenic devices.

The bacteria colonize and transmit from plumbing fittings such as shower heads and hot-water taps. ${ }^{12}$ In India, L. pneumophila was found in 6.66 to $15.2 \%$ of distal outlet waters in patient care areas in tertiary hospitals. ${ }^{13,14}$ Outbreaks of the LD are more common in late summer and early autumn because of stagnation of water which provides an ideal ground for bacterial growth. ${ }^{15}$

In wake of the ongoing pandemic crisis due to coronavirus disease 2019, exposure to aerosolized water from recently reopened office and market buildings is considered as an epidemiologic risk factor for Legionella exposure. ${ }^{16}$ Outbreaks from a dishwasher in a reopened restaurant in Italy, Rome, were reported just after the prolonged lockdown. Stagnating water in the water pipes and dispersing water units such as air conditioning system, and spa pools provide conditions where harmful Legionella can proliferate. $^{17,18}$

\section{Clinical Presentations of Legionella}

Legionellosis is the descriptive terminology used to define infections caused by the members of Legionella including LD, a severe and presumably fatal form of pneumonia, ${ }^{6}$ and PF, a self-limited flu-like illness. Subclinical infections may even go undetected as being entirely asymptomatic. $^{19,20}$ In exceptional cases, Legionella can get transmitted to other organs through the bloodstream and the lymphoid system resulting in extrapulmonary infections. $^{21}$

In all cases, the incubation period is 24 to 48 hours. When an outbreak occurs, more than $90 \%$ of the population exposed to the contaminated aerosol contract PF. Recovery from PF occurs within a week, while the more susceptible population may progress to LD. ${ }^{22}$

\section{Legionnaires Disease}

LD does not have explicit or critical medical features, but presents a wide range of clinical manifestations and symptoms. LD often occurs in elderly patients, immunocompromised patients, smokers, and patients with the history of diabetes and chronic obstructive pulmonary disease. The disease is initially characterized by high fever, fatigue, malaise, and sleeplessness. Additional variable symptoms may include simple cough, ${ }^{23}$ cough with blood-streaked sputum and hemoptysis, or pleuritis. Gastrointestinal symptoms such stomach ache, vomiting, and diarrhea are common. ${ }^{24}$ Some patients also manifest neurologic signs such as neuralgia, disturbed state, lethargy, anxiety, and delusion. ${ }^{25}$ Radiographic manifestations include alveolar opacities and infected pulmonary tissue reveal bronchopneumonia. Airspace inflammation and thrombosis and alveolar wall necrosis can also occur. Often, antibiotic treatment does not reduce the progression of pneumonia even after 5 days.

\section{Pontiac Fever}

$\mathrm{PF}$ is seen in a majority of the population exposed to contaminated aerosols. PF occurs in an acute outbreak mode and is not related to pneumonia. ${ }^{26}$ As with LD, the infection occurs from the inhalation of a Legionella-contaminated aerosol but PF appears in healthy individuals as well. ${ }^{27}$ Clinically, symptoms of PF resemble asthenia, influenza with fever, muscle pain, headache, cough, and pharyngitis. ${ }^{26,28}$ Patients with these symptoms recover without medication in 2 to 5 days. ${ }^{29}$ Unlike LD where pneumonia is the distinct pathology, the pathogenicity of PF is poorly defined. However, age, gender, and smoking habits are underlying risk factors for $\mathrm{LD}$, and these are not notable risk factors for $\mathrm{PF}^{30}$

\section{Extrapulmonary Infections}

L. pneumophila has been isolated from internal organs including lymph glands and alimentary canal indicating that the bacteria spread into different parts of the body through the respiratory system or via surgical sites. ${ }^{31}$ The heart is the most frequently affected organ. ${ }^{32}$ The clinical manifestations of extra pulmonary Legionella are often abrupt with manifestations of erysipelas, peritoneal inflammation, or kidney infection. ${ }^{33}$ Legionella occasionally progress through the nervous system and lead to neurological symptoms of encephalitis, cerebrum infection, and chronic fatigue. ${ }^{34}$

\section{Incidence}

The worldwide prevalence of Legionellosis is mysterious. Although Legionella is a well-known problem, according to World Health Organization, this pathogen is neglected in developing and underdeveloped countries and hence no or limited reports appear from many regions. ${ }^{35}$ Some data from longitudinal research has shown that outbreaks in healthcare systems are more likely to occur when more than $30 \%$ of peripheral sites in the water source are colonized by the pathogen. ${ }^{36}$ Despite the availability of various guidelines and standards for preventing the spread of Legionella and minimizing risks in the healthcare sector, the recorded incidence 
of Legionellosis has risen from 0.42 to 1.62 per 100,000 individuals in the United States from 2000 to $2014 .{ }^{37}$ In Europe, the incidence rate of LD was 2.2 per 100000 in 2018. Reports from Hong Kong and China also report an increase in incidence rate from 0.16 per 100000 in 2005 to 0.91 per 100000 in $2015 .^{38} \mathrm{~A}$ study conducted at a medical care center in India from 2015 to 2020 in patients with confirmed pneumonia found 14 out of 597 patients were positive for Legionella infection. ${ }^{39}$

\section{Diagnostic Methods}

Since the discovery of L. pneumophila, several techniques have been developed to detect the pathogen. Though first reported by culturing in yolk sacs of embryonated eggs, the first diagnostic technique for specific identification of the causal agent employed immunofluorescence labeling. ${ }^{40}$

\section{Conventional Culture Method}

Mueller-Hinton agar accompanied with hemoglobin and IsoVitaleX was the first culture medium used to isolate Legionella. ${ }^{41}$ The medium used for the isolation has undergone several modifications with improvements, resulting in the medium currently used. This conventional culture technique is traditionally recognized as the gold standard for Legionella isolation and detection.

Even though this protocol allows to isolate and quantify legionellae from environmental water, it does have its restrictions. These techniques require extended growth time, they are tedious, retrieval rates are habitually low, and concentration of samples by centrifugation or filtration leads to bacterial cell injury and thus loss. ${ }^{42}$ The most commonly used method for the environmental surveillance of Legionella is the standard culture technique, which allows the estimation of the number of bacteria present in the water. Laboratories across the world follow International Organization for Standardization (ISO) 11731:2017 culturing method for Legionella enumeration. This method is applicable to all kinds of samples such as natural waters, potable, industrial and waste waters and also include water associated matrices such as biofilms and sediments. The bacterial portion of the sample is concentrated by filtration and treated with acid or heat to selectively isolate Legionella. Isolation of Legionella from clinical and environmental samples is currently done on buffered charcoal yeast extract agar base (BCYE) containing 0.1\% alpha-ketoglutarate (ISO 11731:1998). Two types of selective BCYE agar supplemented with antimicrobial agents are included in the standard processing of the environmental samples. The first is designated as PCV that contains polymyxin B, cycloheximide, and vancomycin antibiotics along with BCYE. The second is GPCV that contains glycine, polymyxin, cycloheximide, and vancomycin to inhibit the growth of environmental flora in the medium. PCV without L-cysteine is used as a negative control medium as Legionella fail to grow in the absence of cysteine. ${ }^{40}$ Further strain identification requires additional serological methods. ${ }^{43}$ Presence of other interfering microorganisms and the ability of Legionella to enter into the viable but not-culturable state in limited nutrient conditions further hinder the recovery of Legionella by conventional culture method. The underestimation of Legionella could occur due to failure of Legionella to grow in harsh sample processing conditions and overestimation (false-positives) occurs due to growth of other genera that have evolved to grow in formulated Legionella-specific media. ${ }^{44}$ Alternatively, a coculture protocol for resuscitation of Legionella in the presence of amoeba was developed to promote the intracellular multiplication of Legionella and enhance recovery. ${ }^{43}$ This enrichment takes about 72 to 100 hours for recovery of $\sim 10$ bacteria and the bacteria thus recovered are more invasive and virulent. ${ }^{45}$

\section{Molecular Methods}

Culture-independent methods of detecting have shown higher number of Legionella when compared to the culture technique. ${ }^{46}$ Nucleic acid probe detection methods and polymerase chain reaction (PCR) techniques have been developed or adapted for rapid detection and quantification of Legionella DNA in water samples for routine monitoring. ${ }^{47}$ Molecular methods such as PCR are more sensitive than the culture method. Some of the common targets for PCR-based detection of Legionella are the 5S rDNA, 16S rDNA, the macrophage infectivity potentiator (mip) gene, rpo $\mathrm{B}$, and defective organelle trafficking(dotA) gene of $L$. pneumophila. $^{48,49}$ A comparative study between PCR and culturebased method showed PCR to accurately detect 6\% more samples than culture technique from respiratory samples using the $16 \mathrm{~S}$ rDNA as target. However, ambiguity rests when testing environmental samples: 5S rDNA had higher level of sensitivity than culture methods, while mip and 16S rDNA had same levels of sensitivity. ${ }^{50}$ Not all PCR assays can discriminate between living and nonliving (noninfectious) Legionella cells. Legionella detection for environmental monitoring is a qualitative test and hence quantification is often not reported.

Quantitative (qPCR) amplifies and quantifies a target DNA thereby providing rapid enumeration of Legionella from environmental samples. ${ }^{51}$ A review on 28 studies conducted from 2003 to 2013 that concurrently used culture and qPCR to quantify Legionella from environmental sources showed 26 of 28 studies reporting better sensitivity using qPCR. ${ }^{52}$ The limitations of qPCR include amplification of dead cells, need for optimizing the sample types every time, and presence of inhibiting environmental compounds. ${ }^{53}$

Viability quantitative polymerase chain reaction ( $\mathrm{v}-\mathrm{qPCR}$ ) is a relatively recent analytical approach applied for detecting live Legionella in environmental sample. While v-qPCR yields better or equal sensitivity when compared to the culture method, its sensitivity is lower when compared to qPCR thus establishing that it detects only viable forms. ${ }^{54}$

Loop-mediated isothermal amplification (LAMP) has gained attention for molecular diagnostics due to its higher sensitivity to detect lower nucleic acid concentrations and the ability to perform this test in the absence of any sophisticated equipment. The technique has found applications in the detection and diagnosis of several pathogens. Thus, the 
LAMP assay can be considered as a potential diagnostic tool with higher sensitivity and specificity than conventional methods, such as PCR and culture method. ${ }^{55}$ Recent developments on the application of LAMP for detection of Legionella are listed in - Table 1.

MALDITOF: Matrix-assisted laser desorption ionizationtime-of-flight mass spectrometry (MALDI-TOF MS) has emerged as an advanced, efficient, and low-cost tool for species-level identification using ribosomal protein patterns. ${ }^{63}$ Owing to slow growth and the lack of specific and rapid diagnostic methods, Legionella nonpneumophila species are less commonly identified in clinical diagnosis or environmental sampling. While MALDI-TOF MS is widely used throughout the world, few studies have been published on its use to identify Legionella in clinical and environmental samples. A comparative study was conducted between the cultural and mip-gene sequencing findings. Additionally, phylogenetic analysis was also conducted to quantify the correlations between isolates. In this experiment, MALDITOF MS achieved exact species-level identification for $45.0 \%$ of the isolates displaying a high concordance with the mipgene results. In comparison, the remaining $55.0 \%$ of isolates showed less consistent, as it was not added in the database. The findings support the use of MALDI-TOF MS in routine monitoring, as it provides more accurate and species level identification, as well as the ability to identify species that are not yet in the database. No errors were observed in the result. $^{64}$

\section{Immunological Methods}

While culture methods are time exhaustive but provide for accurate detection, molecular methods provide for rapid but probable nonspecific detection. Immunological methods provide for specific rapid detection using antibodies that are specifically raised against Legionella more specifically against a particular serotype. The direct immunofluorescence assay (DFA) was first used for the discovery of Legionella as a pathogen. DFA is now used to detect Legionella effectively from sputum, endotracheal suction aspirates, and lung biopsies. ${ }^{65}$ This method has the advantage of delivering a report in 2 to 4 hours, but it is technically challenging and can only be practiced by professional laboratory staff. The urinary antigen test is often used in a clinical setting for rapid diagnosis as Legionella gets eliminated via the urine and provides for a noninvasive detection method. Here too, the antibody is specific for a particular serotype, most often $L$. pneumophila serotype 1 . Other species of the genera or other serotypes of L. pneumophila other than that detected by the antibody would get omitted by these methods and hence the immunological methods though specific and rapid have low sensitivity for the detection of Legionella infections. ${ }^{66}$

Table 1 Applications of LAMP in the detection of Legionella

\begin{tabular}{|c|c|c|c|}
\hline Method & Gene target & Outcome & References \\
\hline $\begin{array}{l}\text { LAMP combined } \\
\text { with electrochemi- } \\
\text { cal transduction } \\
\text { system }\end{array}$ & $16 S$ rRNA & $\begin{array}{l}\text { Detects } 10 \mathrm{fg} \text { nucleic acid correspond- } \\
\text { ing to only two copies of the bacteria }\end{array}$ & Olabarria et al $2020^{56}$ \\
\hline $\begin{array}{l}\text { LAMP } \\
\text { Droplet digital } \\
\text { based LAMP }\end{array}$ & $\begin{array}{l}\text { 16SrRNA } \\
\text { Lep } B\end{array}$ & $\begin{array}{l}10^{3} \mathrm{fg}_{\mathrm{\mu L}}^{-1} \\
1,233 \text { droplets with positive target } \\
\text { DNA amplification out of } 9103 \text { drop- } \\
\text { lets for the lep } B \text { gene sequence }\end{array}$ & Reuter et al $2020^{57}$ \\
\hline LAMP & Mip & $\begin{array}{l}\text { 1\% culture positive } \\
3 \% \text { PCR positive } \\
\text { 7\% LAMP positive } \\
\end{array}$ & Moosavian et al $2019^{55}$ \\
\hline $\begin{array}{l}\text { Multiplex isother- } \\
\text { mal RPA } \\
\text { amplification }\end{array}$ & Mip & $10 \mathrm{CFU}$ & Kersting et al $2018^{58}$ \\
\hline LAMP & $16 S$ rRNA & $\begin{array}{l}\text { 31.9\%- LAMP for water sample } \\
5.8 \% \text { culture method } \\
11.1 \% \text {-LAMP swab sample } \\
1.1 \% \text {-culture method }\end{array}$ & Kuroki et al $2017^{59}$ \\
\hline $\begin{array}{l}\text { Real time LAMP on- } \\
\text { filter direct } \\
\text { amplification }\end{array}$ & 16SrRNA, cadA & $\sim 1 \mathrm{CFU} / 100 \mathrm{~mL}$ & Samhan et al $2017^{60}$ \\
\hline Real time LAMP & $16 S$ rRNA & $\begin{array}{l}\text { LAMP } 56.07 \% \\
\text { Culture assay } 47.66 \%\end{array}$ & Lu et al $2011^{61}$ \\
\hline LAMP & $\begin{array}{l}\text { 16SrRNA gene to } \\
\text { detect wide range } \\
\text { of Legionella spp. }\end{array}$ & detection limit 6 CFU per test & Annaka $2003^{62}$ \\
\hline
\end{tabular}

Abbreviations: CFU, colony forming unit; LAMP, Loop-mediated isothermal amplification; PCR, polymerase chain reaction; RPA, recombinase polymerase amplification. 
The use of polyclonal antibodies or various monoclonal antibodies can provide for a broader spectrum of sensitivity. However, cross reactivity within the antibodies can give false positive results. ${ }^{46}$ This method detects and enumerates $L$. pneumophila within 3 to 4 hours. However, immunological methods and molecular methods detect both viable and nonviable cells.

ELISA: Tilton was the first to develop enzyme-linked immunosorbent assay (ELISA) to identify a soluble antigen in patients urine infected by L. pneumophila serogroup 1 (L.pn 1) and several other assays have since been published. For the detection of specific antibodies to serogroup 1 and each of the six serogroups of $L$. pneumophila, ELISA has been found to give many advantages over standard indirect fluorescent antibody and other serological tests in terms of simplicity, rapidity, quantitative measurement, and automation ability. ${ }^{67}$ Crossreactivity between serogroups or species is typical in commercial ELISA kits that use L. pneumophila whole-cell protein as the coating antigen. A study conducted by Sun et al using L. pneumophila proteins such as FLA (Flagellin A), MOMP (major outer membrane protein), MIP (macrophage infectivity potentiator), and PILE (type IV pilin) IP, and PILE (Type IV pilin) applied in serological diagnosis of $L$. pneumophila infections compared with Legionella ELISA kits. The results of the five purified proteins used in indirect ELISA revealed that IgG had a sensitivity of $90.4 \%$ and a specificity of $97.4 \%$. The proteins seemed to be suitable coating antigens for the serological diagnosis of L. pneumophila. ${ }^{68}$

\section{Physicochemical Methods to Indicate Legionella spp.}

The biggest hurdle to detect Legionella is its fastidious nature. The conventional culturing technique considered as the benchmark detection can take up to 14 days to give a result. Therefore, rapid detection methods are the need of the hour for disease prevention and management of outbreaks if any. ${ }^{69}$ One approach to develop a low cost, low infrastructure, and rapid detection method is to detect environmental indicators for the pathogen of interest. Among many transition metals, iron, copper, zinc, and magnesium act as cofactors for many biological enzymes. More often than not the microorganisms source these metal ions from their immediate environment. Thus, screening of concentration of essential metal ions allows development of sensitive and specific assay for the detection of sites that favor the growth of microorganism of concern.

Iron is associated with many enzymes linked with respiratory chains. Since legionellae are iron-dependent, it is often expected that their growth will be promoted by the use of iron piping and in water containing high levels of iron. Iron positively correlates with Legionella. ${ }^{70}$ We have reported that iron concentration of $300 \mathrm{mg} \mathrm{Fe} / \mathrm{L}$ in cooling tower water shows a positive correlation with Legionella presence and could be used as a strong indicator of Legionella. ${ }^{71}$

Copper pipes have been found to temporarily restrict colonization by Legionella and hence may not be a suitable indicator for this pathogen. ${ }^{72}$
Zinc has been associated with lower levels of Legionella, suggesting that between 100 and $200 \mathrm{ppb}$ may be the optimal amount of zinc for Legionella growth. ${ }^{73}$ Manganese levels below $3 \mu \mathrm{g} / \mathrm{L}$ are correlated with less number of Legionella, but a negative association appears to exist above $10 \mu \mathrm{g} / \mathrm{L}^{74}$ Conflicting results were found with respect to the calcium and Legionella interactions, with two experiments showing favorable, one negative, and another noncorrelated results. ${ }^{75}$ Overall, among the inorganic ions that are present in water, iron seems to be the only parameter that consistently appears along with Legionella thus being a suitable indicator for the pathogen.

\section{Conclusion}

The incidence of Legionella infection is underdiagnosed in many parts of the world due to lack of optimal diagnostic tests. To improve the diagnosis protocols, in terms of specificity and sensitivity, newer methods are being developed to understand the epidemiology of LD. Recent advances in the Legionella detection include PCR-based methods. However, combinatorial tests based on culture, serological testing, urinary antigen detection, and analytical techniques continue to be the first line of investigation in many medical microbiology laboratories. The better availability and use of improved diagnostic tests will help to better characterize the epidemiology of $L D$, including the true incidence and geographic variation.

Conflict of Interest

None declared.

\section{References}

1 Mercante JW, Winchell JM. Current and emerging Legionella diagnostics for laboratory and outbreak investigations. Clin Microbiol Rev 2015;28(01):95-133

2 Newton HJ, Ang DK, van Driel IR, Hartland EL. Molecular pathogenesis of infections caused by Legionella pneumophila. Clin Microbiol Rev 2010;23(02):274-298

3 Fields BS, Benson RF, Besser RE. Legionella and Legionnaires' disease: 25 years of investigation. Clin Microbiol Rev 2002;15 (03):506-526

4 Mekkour M, Khalil E, Driss B, Tai J, Cohen N. Legionella pneumophila: an environmental organism and accidental pathogen. Int J Sci Technol 2013;2(02):187-196

5 Colbourne JS, Dennis PJ, Trew RM, Berry C, Vesey G. Legionella and public water supplies. Water Sci Technol 1988;20(11-12)5-10

6 Fliermans CB, Cherry WB, Orrison LH, Smith SJ, Tison DL, Pope DH. Ecological distribution of Legionella pneumophila. Appl Environ Microbiol 1981;41(01):9-16

7 Hoge CW, Breiman RF. Advances in the epidemiology and control of Legionella infections. Epidemiol Rev 1991;13(01):329-340

8 Steinert M, Hentschel U, Hacker J. Legionella pneumophila: an aquatic microbe goes astray. FEMS Microbiol Rev 2002;26(02): 149-162

9 Heng BH, Goh KT, Ng DL, Ling AE. Surveillance of legionellosis and Legionella bacteria in the built environment in Singapore. Ann Acad Med Singap 1997;26(05):557-565

10 Leoni E, Legnani PP, Bucci Sabattini MA, Righi F. Prevalence of Legionella spp. in swimming pool environment. Water Res 2001; 35(15):3749-3753 
11 Atlas RM. Legionella: from environmental habitats to disease pathology, detection and control. Environ Microbiol 1999;1 (04):283-293

12 Bollin GE, Plouffe JF, Para MF, Hackman B. Aerosols containing Legionella pneumophila generated by shower heads and hotwater faucets. Appl Environ Microbiol 1985;50(05):1128-1131

13 Chaudhry R, Sreenath K, Arvind V, Vinayaraj EV, Tanu S. Legionella pneumophila serogroup 1 in the water facilities of a tertiary healthcare center, India. Emerg Infect Dis 2017;23(11): 1924-1925

14 Jinna S, Gaikwad UN. Environmental surveillance of Legionella pneumophila in distal water supplies of a hospital for early identification \& prevention of hospital-acquired legionellosis. Indian J Med Res 2018;147(06):611-614

15 Burillo A, Pedro-Botet ML, Bouza E. Microbiology and epidemiology of Legionnaire's disease. Infect Dis Clin North Am 2017;31 (01):7-27

16 Cassell K, Davis JL, Berkelman R. Legionnaires' disease in the time of COVID-19. Pneumonia (Nathan) 2021;13(01):2

17 Palazzolo C, Maffongelli G, D'Abramo Aet al.Legionella pneumonia: increased risk after COVID-19 lockdown? Italy, May to June 2020. Euro Surveill 2020;25(30):2001372

18 Rota MC, Scaturro M, Ricci ML. Letter to the editor: importance of a careful investigation to avoid attributing Legionnaires' disease cases to an incorrect source of infection. Euro Surveill 2020;25 (34):2001484

19 Boshuizen HC, Neppelenbroek SE, van Vliet Het al.Subclinical Legionella infection in workers near the source of a large outbreak of Legionnaires disease. J Infect Dis 2001;184(04):515-518

20 Nagelkerke NJ, Boshuizen HC, de Melker HE, Schellekens JF, Peeters MF, Conyn-van Spaendonck M. Estimating the incidence of subclinical infections with Legionella Pneumonia using data augmentation: analysis of an outbreak in The Netherlands. Stat Med 2003;22(24):3713-3724

21 Amodeo MR, Murdoch DR, Pithie AD. Legionnaires' disease caused by Legionella longbeachae and Legionella pneumophila: comparison of clinical features, host-related risk factors, and outcomes. Clin Microbiol Infect 2010;16(09):1405-1407

22 WHO G. Guidelines for drinking-water quality. World Health Organization 2011; 216:303-304. Available at: https://apps. who.int/iris/bitstream/handle/10665/44584/ 9789241548151_eng.pdf;jsessionid=30C418A2B8231AFBCA0956BC8989DCF9? sequence $=1$ (Accessed on 12 May 2021)

23 Chidiac C, Che D, Pires-Cronenberger Set al.French Legionnaires' Disease Study Group. Factors associated with hospital mortality in community-acquired legionellosis in France. Eur Respir J 2012; 39(04):963-970

24 Mulazimoglu L, Yu VL. Can Legionnaires disease be diagnosed by clinical criteria? A critical review. Chest 2001;120(04): 1049-1053

25 Jespersen S, Søgaard OS, Schønheyder HC, Fine MJ, Østergaard L. Clinical features and predictors of mortality in admitted patients with community- and hospital-acquired legionellosis: a Danish historical cohort study. BMC Infect Dis 2010;10(01):124

26 Pancer K, Stypułkowska-Misiurewicz H. [Pontiac fever-non-pneumonic legionellosis]. Przegl Epidemiol 2003;57(04):607-612

27 Fields BS, Haupt T, Davis JP, Arduino MJ, Miller PH, Butler JC. Pontiac fever due to Legionella micdadei from a whirlpool spa: possible role of bacterial endotoxin. J Infect Dis 2001;184(10): 1289-1292

28 Castor ML, Wagstrom EA, Danila RNet al.An outbreak of Pontiac fever with respiratory distress among workers performing highpressure cleaning at a sugar-beet processing plant. J Infect Dis 2005;191(09):1530-1537

29 Avril JL, Dabernat H, Denis F, Monteil H. Epidémiologie et pouvoir pathogène de Legionella. In: Bactériologie Clinique Edited by: Ellipses. Paris1992:309-18
30 Friedman S, Spitalny K, Barbaree J, Faur Y, McKinney R. Pontiac fever outbreak associated with a cooling tower. Am J Public Health 1987;77(05):568-572

31 Lowry PW, Tompkins LS. Nosocomial legionellosis: a review of pulmonary and extrapulmonary syndromes. Am J Infect Control 1993;21(01):21-27

32 Stout JE, Yu VL, Muraca P. Isolation of Legionella pneumophila from the cold water of hospital ice machines: implications for origin and transmission of the organism. Infect Control 1985;6 (04):141-146

33 Eitrem R, Forsgren A, Nilsson C. Pneumonia and acute pancreatitis most probably caused by a Legionella longbeachae infection. Scand J Infect Dis 1987;19(03):381-382

34 Shelburne SA, Kielhofner MA, Tiwari PS. Cerebellar involvement in legionellosis. South Med J 2004;97(01):61-64

35 Phin N, Parry-Ford F, Harrison Tet al.Epidemiology and clinical management of Legionnaires' disease. Lancet Infect Dis 2014;14 (10):1011-1021

36 Ozerol IH, Bayraktar M, Cizmeci Zet al.Legionnaire's disease: a nosocomial outbreak in Turkey. J Hosp Infect 2006;62(01):50-57

37 Garrison LE, Kunz JM, Cooley LAet al.Vital signs: deficiencies in environmental control identified in outbreaks of Legionnaires' disease-North America, 2000-2014. MMWR Morb Mortal Wkly Rep 2016;65(22):576-584

38 Zemouri C, Awad SF, Volgenant CM. Crielaard W, Laheij AMGA, de Soet JJ. Modeling of the transmission of coronaviruses, measles virus, influenza virus, Mycobacterium tuberculosis, and Legionella pneumophila in dental clinics. J Dent Res 2020;99(10): 1192-1198

39 Sreenath K, Dey AB, Kabra SK, Thakur B, Guleria R, Chaudhry R. Legionella pneumophila in patients with pneumonia at a referral hospital, New Delhi, India, 2015-2020. Am J Trop Med Hyg 2020; 14:tpmd-200653

40 Cherry WB, Pittman B, Harris PPet al.Detection of Legionnaires disease bacteria by direct immunofluorescent staining. J Clin Microbiol 1978;8(03):329-338

41 Berdal BP, Farshy CE, Feeley JC. Detection of Legionella pneumonophila antigen in urine by enzyme-linked immunospecific assay. J Clin Microbiol 1979;9(05):575-578

42 Villari P, Motti E, Farullo C, Torre I. Comparison of conventional culture and PCR methods for the detection of Legionella pneumophila in water. Lett Appl Microbiol 1998;27(02):106-110

43 Fields BS. The molecular ecology of legionellae. Trends Microbiol 1996;4(07):286-290

44 Delgado-Viscogliosi P, Simonart T, Parent Vet al.Rapid method for enumeration of viable Legionella pneumophila and other Legionella spp. in water. Appl Environ Microbiol 2005;71(07): 4086-4096

45 Cirillo JD, Falkow S, Tompkins LS. Growth of Legionella pneumophila in Acanthamoeba castellanii enhances invasion. Infect Immun 1994;62(08):3254-3261

46 Aurell H, Catala P, Farge Pet al.Rapid detection and enumeration of Legionella pneumophila in hot water systems by solid-phase cytometry. Appl Environ Microbiol 2004;70(03):1651-1657

47 Hay J, Seal DV, Billcliffe B, Freer JH. Non-culturable Legionella pneumophila associated with Acanthamoeba castellanii: detection of the bacterium using DNA amplification and hybridization. J Appl Bacteriol 1995;78(01):61-65

48 Cloud JL, Carroll KC, Pixton P, Erali M, Hillyard DR. Detection of Legionella species in respiratory specimens using PCR with sequencing confirmation. J Clin Microbiol 2000;38(05): 1709-1712

49 Grattard F, Ginevra C, Riffard Set al.Analysis of the genetic diversity of Legionella by sequencing the 23S-5S ribosomal intergenic spacer region: from phylogeny to direct identification of isolates at the species level from clinical specimens. Microbes Infect 2006;8(01):73-83 
50 Blanco S, Prat C, Sánchez MD et al. Evaluation of a Legionella urinary antigen enzyme immunoassay for rapid detection of Legionella pneumophila in water samples. Int J Hyg Environ Health 2008;211(01/02):168-171

51 Parthuisot N, Binet M, Touron-Bodilis A, Pougnard C, Lebaron P, Baudart J. Total and viable Legionella pneumophila cells in hot and natural waters as measured by immunofluorescence-based assays and solid-phase cytometry. Appl Environ Microbiol 2011;77(17):6225-6232

52 Whiley $\mathrm{H}$, Taylor M. Legionella detection by culture and qPCR: comparing apples and oranges. Crit Rev Microbiol 2016;42(01):65-74

53 Brooks T, Osicki R, Springthorpe Vet al.Detection and identification of Legionella species from groundwaters. J Toxicol Environ Health A 2004;67(20/22):1845-1859

54 Lizana X, López A, Benito Set al.Viability qPCR, a new tool for Legionella risk management. Int J Hyg Environ Health 2017;220 (08):1318-1324

55 Moosavian M, Seyed-Mohammadi S, Saki Met al.Loop-mediated isothermal amplification for detection of Legionella pneumophila in respiratory specimens of hospitalized patients in Ahvaz, southwest Iran. Infect Drug Resist 2019;12:529-534

56 Olabarria G, Eletxigerra U, Rodriguez I, Bilbao A, Berganza J, Merino S. Highly sensitive and fast Legionella spp. in situ detection based on a loop mediated isothermal amplification technique combined to an electrochemical transduction system. Talanta 2020;217:121061

57 Reuter C, Slesiona N, Hentschel Set al.Loop-mediated amplification as promising on-site detection approach for Legionella pneumophila and Legionella spp. Appl Microbiol Biotechnol 2020;104(01):405-415

58 Kersting S, Rausch V, Bier FF, von Nickisch-Rosenegk M. A recombinase polymerase amplification assay for the diagnosis of atypical pneumonia. Anal Biochem 2018;550:54-60

59 Kuroki T, Watanabe Y, Teranishi H, Izumiyama S, Amemura-Maekawa J, Kura F. Legionella prevalence and risk of legionellosis in Japanese households. Epidemiol Infect 2017;145(07):1398-1408

60 Samhan FA, Stedtfeld TM, Waseem H, Williams MR, Stedtfeld RD, Hashsham SA. On-filter direct amplification of Legionella pneumophila for rapid assessment of its abundance and viability. Water Res 2017;121:162-170

61 Lu X, Mo ZY, Zhao HB, Yan H, Shi L. LAMP-based method for a rapid identification of Legionella spp. and Legionella pneumophila. Appl Microbiol Biotechnol 2011;92(01):179-187
62 Annaka T. Rapid and simple detection of Legionella species by LAMP, a mew DNA amplification method. Rinsho Biseibutsu Jinsoku Shindan Kenkyukai shi=JARMAM. J Rapid Meth Aut Mic. 2003;14(01):25-30

63 Croxatto A, Prod'hom G, Greub G. Applications of MALDI-TOF mass spectrometry in clinical diagnostic microbiology. FEMS Microbiol Rev 2012;36(02):380-407

64 Dilger T, Melzl H, Gessner A. Rapid and reliable identification of waterborne Legionella species by MALDI-TOF mass spectrometry. J Microbiol Methods 2016;127:154-159

65 Stout JE, Rihs JD, Yu VL. Legionella. In: Murray PR, Baron EJ, eds. Manual of Clinical Microbiology. 8th ed. Washington DC:. ASM Press; 2003:809-823

66 Dionne M, Hatchette T, Forward K. Clinical utility of a Legionella pneumophila urinary antigen test in a large university teaching hospital. Can J Infect Dis 2003;14(02):85-88

67 Sampson JS, Wilkinson HW, Tsang VC, Brake BJ. Kinetic-dependent enzyme-linked immunosorbent assay for detection of antibodies to Legionella pneumophila. J Clin Microbiol 1983;18(06): 1340-1344

68 Sun H, Ma H, Liu L, Cao X, Yang Z. A new ELISA method for serological diagnosis of Legionella pneumophila: use of five purified proteins, FLA, MOMP, MIP, IP, and PILE, as diagnostic antigen. Clin Lab 2015;61(3-4)275-282

69 Benowitz I, Fitzhenry R, Boyd Cet al.Rapid identification of a cooling tower-associated legionnaires' disease outbreak supported by polymerase chain reaction testing of environmental samples, New York City, 2014-2015. J Environ Health 2018;80 (08):8-12

70 van der Lugt W, Euser SM, Bruin JP, Den Boer JW, Walker JT, Crespi S. Growth of Legionella anisa in a model drinking water system to evaluate different shower outlets and the impact of cast iron rust. Int J Hyg Environ Health 2017;220(08):1295-1308

71 Vittal R, Raj JRM, Kumar BK, Karunasagar I. Iron content as an indicator for Legionella species in artificial water systems. Med Leg Update 2021;21(01):803-808

72 van der Kooij D, Veenendaal HR, Scheffer WJ. Biofilm formation and multiplication of Legionella in a model warm water system with pipes of copper, stainless steel and cross-linked polyethylene. Water Res 2005;39(13):2789-2798

73 Zacheus OM, Martikainen PJ. Occurrence of legionellae in hot water distribution systems of Finnish apartment buildings. Can J Microbiol 1994;40(12):993-999 